\title{
"SOZINHOS NÃO VAMOS VENCER": PRÁTICAS COLABORATIVAS E GANHOS COLETIVOS EM UMA REDE DE EMPREENDIMENTOS DA ECONOMIA SOLIDÁRIA BRAZIL
}

\author{
Tatiane Martins Cruz Pirotti \\ Mestranda em Administração \\ Universidade do Vale do Rio dos Sinos - UNISINOS \\ São Leopoldo - Rio Grande do Sul - Brasil \\ tatianetika@yahoo.com.br \\ Cláudia Cristina Bitencourt \\ Doutora em Administração \\ Universidade do Vale do Rio dos Sinos - UNISINOS \\ São Leopoldo - Rio Grande do Sul - Brasil \\ claudiacb@unisinos.br \\ Douglas Wegner \\ Doutor em Administração \\ Universidade do Vale do Rio dos Sinos - UNISINOS \\ São Leopoldo - Rio Grande do Sul - Brasil \\ dwegner@unisinos.br
}

\section{RESUMO}

Este artigo se propõe a identificar as principais práticas colaborativas utilizadas por uma rede formada por Empreendimentos de Economia Solidária de reciclagem, para a geração de ganhos coletivos. Para tanto, foi utilizado o método de estudo de caso e a coleta de dados foi feita por meio de observações e da realização de sete entrevistas. As principais práticas colaborativas identificadas são: troca de informações, formação de grupos de trabalho para busca de objetivos da rede, parcerias para realização de formações, "intercâmbio" de trabalhadores entre os empreendimentos participantes, manifestações, organização coletiva para busca de recursos. Os ganhos gerados por meio destas práticas podem ser associados às categorias propostas por Podolny e Page (1998): aprendizagem, legitimação e status, e benefícios financeiros. Os resultados demonstram a importância da rede para o desenvolvimento e atuação dos empreendimentos que dela fazem parte e para os indivíduos que nela se inserem. Como contribuição teórica, esse estudo confirma a relação positiva entre as práticas colaborativas utilizadas em redes de empreendimentos da economia solidária e as categorias de ganhos apresentadas na literatura. Outra contribuição teórica consiste em evidenciar uma nova categoria de ganho denominada de empoderamento dos indivíduos, específica do contexto estudado. A contribuição gerencial desse estudo consiste em descrever um conjunto de práticas que podem ser utilizadas por outros empreendimentos solidários operando em rede.

Palavras-chave: Economia solidária; Ganhos coletivos; Práticas colaborativas; Redes de cooperação.

\section{"WE ARE NOT GOING TO WIN ALONE": COLLABORATIVE PRACTICES AND COLLECTIVE GAINS IN A NETWORK OF SOLIDARITY ECONOMY IN BRAZIL}

\begin{abstract}
This paper aims to identify collaborative practices used by a network of Solidarity Economy to generate collective gains. We followed a qualitative research approach, performed through observation and seven interviews. The main collaborative practices adopted by the organizations were: sharing information between organizations, creating specific working groups to look for new opportunities, formal training, workers exchange among the participating organizations, use of public spaces to show their needs, and collective search for resources. The results demonstrate the importance of the network for the development and the operation of the participating organizations so as for the individuals who compose the organizations. As a theoretical contribution, our results confirm a positive relationship between the collaborative practices performed by a network of solidarity organizations and collective gains on the literature. Another theoretical contribution consists in evidencing a new category of gain called empowerment of individuals, specific to the context studied. The managerial contribution of this paper lies in showing a set of practices that may be used by other networks of solidarity organizations to reach better results.
\end{abstract}

Key words: Cooperation networks, Collaborative practice; Collective gains; Solidarity economy. 


\section{INTRODUÇÃO}

O movimento das organizações para se estruturarem em redes para obtenção de ganhos coletivos não é algo recente. Castells (1999) aponta que a atuação em rede já era uma prática bastante fortalecida nos países de cultura oriental e que nas últimas décadas ganhou cada vez mais espaço no Ocidente. Esta adaptação ocorre especialmente pela necessidade de flexibilidade, pela velocidade tecnológica e pela atuação das empresas impulsionada pela globalização.

Tal ideia é reforçada pelo crescente o número de pesquisas que sugere que os laços entre organizações fornecem recursos que atribuem vários benefícios (Gulati et al., 2011). Embora diversas áreas de conhecimento se dediquem ao estudo das redes, pode-se dar destaque ao interesse sociológico por estas formas organizacionais, que é atribuído à crítica aos modelos econômicos mais tradicionais de organizações, uma vez que busca dar destaque às vantagens e funcionalidade das redes, que não se encaixam nas definições de mercados ou hierarquias já conhecidas (Podolny \& Page, 1998).

Em termos de sustentabilidade dos negócios, Godoy (2008) afirma que a crescente e constante competição é um fator que predomina na atualidade. As organizações adotam diferentes práticas visando manterem-se em atividade, recorrendo a fusões, aquisições e também parcerias com outras empresas, ou seja, práticas como a colaboração passam a ser fundamentais para a sobrevivência de várias formas organizacionais. Em concordância, para Roome e Louche (2016), as necessárias contribuições das organizações para sustentabilidade, ocorrem, muitas vezes, mediante novos modelos de negócios, formados por meio das interações entre indivíduos e grupos dentro e fora das instituições.

Considerando-se este contexto, Gaiger (1998) aponta que, em razão das modificações ocorridas na economia nos últimos anos, se fortaleceu o surgimento dos empreendimentos de Economia Solidária como uma alternativa ao desemprego, gerando novas oportunidades para muitos trabalhadores. Esses empreendimentos são parte da chamada Economia Solidária e, por esta razão, possuem seus princípios norteadores centrados na democracia, na cooperação e na autogestão, além de considerar a melhoria das condições de trabalho e a qualidade de vida acima do lucro (Singer, 2002). De acordo com mapeamento realizado em 2013, foram identificados no Brasil mais de 19 mil Empreendimentos de Economia Solidária, que juntos totalizam mais de 1.400 .000 sócios participantes. Destaca-se que, neste mesmo levantamento, 513 empreendimentos referem atuar na coleta, triagem e ou reciclagem de resíduos (Sies, 2013).

No entanto, ainda que os empreendimentos de Economia Solidária possam ser expressivos em quantidade de participantes, possuam características e princípios específicos, também possuem a necessidade de permanecerem competitivos diante das demais organizações atuantes em seus ramos de atividade, visto que precisam se sustentar economicamente, obtendo um faturamento que possa gerar renda para seus associados. De acordo com o Conselho Nacional de Economia Solidária (2015), existem fraquezas que precisam ser superadas pelos empreendimentos participantes, como, por exemplo, a falta de uma figura jurídica de Empreendimento Econômico Solidário, bem como a dificuldade de acesso a recursos públicos.

Ao analisar-se especificamente os desafios dos empreendimentos solidários vinculados à reciclagem, diversos problemas podem ser constatados. Esses grupos sofrem discriminação por parte da sociedade, sendo a parte mais frágil da complexa cadeia de resíduos, devido à dependência de intermediários, o que torna seus ganhos escassos (Rodrigues \& Ichikawa, 2015). Mesmo nos casos em que os compradores são as indústrias de reciclagem, os recicladores, ou suas cooperativas, encontram-se também em papel de subordinação, sendo influenciados na execução de processo para entrega conforme demanda ou padrões estabelecidos pelos compradores. Tais critérios, estabelecidos na relação de compra, acarretam em outros desafios, como a carência de trabalhadores qualificados, necessidade de conhecimento sobre os materiais triados e os valores de cada um para definir prioridades, equipamentos específicos. A ausência destes promove maior carga de trabalho, o que impacta na qualidade de vida e saúde destes trabalhadores (Santos et al., 2016).

Revista de Gestão Social e Ambiental - RGSA, São Paulo, v. 11, n. 3, p. 37-55, set./dez. 2017. 
Tem-se, ainda, como desafios para estes empreendimentos a privação de direitos, pela falta de vínculo empregatício, a disputa entre pares por materiais e a falta de inserção em sistemas de gestão de resíduos. Mesmo quando organizados em grupos, a informalidade associada ao trabalho de reciclagem, que resulta na alternância com outras atividades formais ou informais, tende a dificultar os vínculos, a continuidade dos trabalhos desenvolvidos e a execução das ações planejadas (Bortoli, 2009). Deste modo, a formação das redes se apresenta como alternativa aos desafios inerentes aos EESs de reciclagem.

Considerando-se que os princípios da Economia Solidária remetem às práticas de cooperação, a atuação em rede parece ser facilmente permitida como uma das formas de fortalecimento e obtenção de ganhos pelos empreendimentos de economia solidária. Desta forma, emerge a questão de pesquisa: quais são as práticas colaborativas utilizadas por uma rede de Empreendimentos de Economia Solidária de reciclagem para a geração de ganhos coletivos? A identificação dessas práticas colaborativas gera contribuições à teoria e à prática, uma vez que amplia o entendimento sobre como a cooperação pode gerar benefícios em empreendimentos com características distintas daquelas normalmente pesquisadas nos estudos sobre redes interorganizacionais empresariais. Para alcance deste objetivo, o artigo está estruturado nas seguintes seções: fundamentação teórica, seguida pelo método utilizado para a pesquisa, posteriormente é demonstrada a análise dos resultados obtidos e, por fim, são apresentadas as considerações finais do estudo.

\section{FUNDAMENTAÇÃO TEÓRICA}

Com o intuito de encontrar o entendimento do tema proposto, a fundamentação teórica apresenta elementos que demonstram características dos empreendimentos de Economia Solidária e, posteriormente, de Redes de Cooperação direcionando-se para as definições que mais se aproximam da rede utilizada como estudo de caso, que será apresentada no capítulo 4.

\subsection{Empreendimentos de Economia Solidária}

A Economia Solidária se origina principalmente da vontade de realização da organização coletiva do trabalho (como as cooperativas, as mutualidades e as associações), de maneira sustentável, autogestionária e como uma opção a sistemática capitalista. As principais demandas associadas são: acesso ao trabalho, melhores condições de vida, direitos políticos, dignidade ao trabalhador, entre outros. Pela autogestão, todos os indivíduos exercem o mesmo poder de escolha e possuem um papel mais abrangente do que teriam atuando como funcionários em uma empresa tradicional (Coelho \& Godoy, 2011).

É possível dizer que a perspectiva da economia solidária enfatiza as interações entre o terceiro setor e a evolução de políticas públicas. A globalização, a terceirização e as tendências sociodemográficas de longo prazo acabam fazendo com que associações operem neste setor. Além disto, diferentes formas de regulação ainda surgem com supervisão do Estado e os pesos destas formas variam, dependendo tanto do tipo de estado de bem-estar, como da configuração de redes de iniciativas (Laville, 2000). Ressalta-se que os resultados obtidos pela Economia Solidária, nascem da auto-organização, no sentido de defesa dos direitos básicos do trabalho, o que parece ser indissociável de sua essência, fundamentando-se principalmente na associação e em soluções coletivas, formando assim uma base de experiências e de convicções morais e intelectuais para a sociedade (Cattani et al., 2009).

Considerados a célula propulsora da Economia Solidária, juntamente com suas vinculações, os Empreendimentos Econômicos Solidários (EES) compreendem a livre associação entre trabalhadores, baseada na cooperação, por meio da socialização dos meios de produção e da autogestão. A solidariedade é o que suporta estes empreendimentos e, ao mesmo tempo, que geram resultados materiais efetivos, também oportunizam ganhos extraeconômicos. Este formato de 
trabalho consorciado age em favor dos próprios associados e confere, ao entendimento de eficiência, maior amplitude, incluindo satisfação e qualidade de vida dos trabalhadores (Cattani et al., 2009).

Baseados nos princípios de cooperação e solidarismo, estes EESs têm como objetivo a geração de renda para seus integrantes, assim como o atendimento de necessidades materiais e sociais de seus membros, além de estimular o envolvimento comunitário e cidadão, ou seja, a inclusão social é promovida por meio destes aspectos (Gaiger, 1998). Além disto, para Coelho e Godoy (2011), os EESs também podem ser vistos como arranjos organizacionais que, por meio de suas práticas, estabelecem momentos de aprendizagem, que são capazes de desenvolver conhecimentos técnicos, sociais e políticos de seus associados.

Já Gaiger (2015), define Empreendimento de Economia Solidária, destacando que: o que se refere a "empreendedorismo" está relacionado ao conjunto de iniciativas destinadas a assegurar o funcionamento das atividades produtivas do EES, com isso propicia-se a remuneração e demais benefícios a seus integrantes. Também deve garantir a sustentabilidade do EES a médio e longo prazo, considerando-se, nesse aspecto, a manutenção do quadro de sócios, assim como do meio social e ambiental em que se inserem tais atividades. Já o "solidarismo" refere-se à inclusão equitativa de todos os membros, à participação igualitária nas decisões, à cooperação produtiva e social nas atividades internas do EES, assim como ao seu envolvimento em questões externas de interesse coletivo, em âmbito comunitário, local ou mais amplo.

Diante das definições expostas, pode-se inferir que a atuação dos EES é baseada na cooperação e nas relações intraorganizacionais (foco nos indivíduos associados a cada EES) ou interorganizacionais, nas relações de mercado para geração de resultados financeiros ou, mesmo, no âmbito da economia solidária, para promoção da cidadania e inclusão social. Considerando-se estes aspectos, a seguir, são apresentados os conceitos sobre redes de cooperação que podem ser mais notoriamente associados à organização objeto deste estudo.

\subsection{Redes de cooperação}

Jarillo (1993) aponta que as redes surgem como uma nova forma organizacional que se diferencia das opções de subcontratar fornecedores (mercado) ou de verticalizar o processo adquirindo mais etapas na cadeia produtiva (hierarquia), baseando-se principalmente nas relações de longo prazo e na confiança estabelecida entre as partes para continuidade da cooperação em futuras oportunidades. Para Raab e Kenis (2009), especialmente nos últimos anos, as sociedades ocidentais estão se movendo em direção a uma sociedade de redes, ou seja, as organizações formais, verticalmente integradas e que dominaram o século XX estão sendo substituídas ou complementadas por criações dirigidas a um objetivo comum em redes organizacionais.

O termo rede é definido por Castells (1999), de forma abrangente e ao mesmo tempo simples, como um conjunto de nós que estão conectados entre si. O autor ainda aponta que as redes estabelecem uma nova forma de estruturação social, sendo que a difusão da lógica de redes é impactante e modifica as formas de operação e obtenção de resultados por meio dos processos produtivos, de experiência, de poder e cultura. Nas organizações em rede, os objetivos, assim como a mudança de objetivos, modelam e remodelam a estrutura dos meios estabelecidos, sendo que, ao mesmo tempo que os componentes da rede são autônomos, dependem uns dos outros e diversos modelos de atuação podem ocorrer. Assim, a organização em rede é vista como uma estratégia de adaptação e sobrevivência das organizações.

Todeva (2006) reforça esta ideia ao dizer que negócios na forma de redes são uma estrutura de relacionamentos entre diferentes atores que visam um objetivo de negócio ou mesmo de recursos. Estas redes são, simultaneamente, estruturas sociais de laços (conexões) e facilitadoras das relações e trocas.

Além dos aspectos até aqui elencados, de redes como formas organizacionais diferenciadas (Jarillo, 1993), com objetivos comuns (Raab \& Kenis, 2009), com alterações em resultados 
alcançados e até mesmo na própria estrutura da rede (Castells, 1999), neste estudo é dada ênfase ao modelo de rede horizontal, que é formado por instituições de um mesmo segmento produtivo, que possuem objetivos comuns e que se aliam para ampliar e proteger sua competitividade, sem perda da autonomia (Wegner, 2011). Entende-se que tais características podem ser associadas a rede objeto do estudo.

Desta forma, as chamadas alianças horizontais são aquelas que ligam organizações da mesma indústria para uma situação de cooperação. Sendo que estas podem acabar por competir em um mesmo mercado (Silverman \& Baum, 2002). No caso a seguir apresentado, em razão dos preceitos de cooperação e fortalecimento do grupo e pela atuação em localidades distintas, não é estabelecida competição entre os integrantes da rede, mas, excluindo-se esse fator, acredita-se que existe uma adequação desta com a definição de redes horizontais.

Este estudo pode se relacionar ainda com a definição de Podolny e Page (1998) de que uma organização em rede é um conjunto de atores que busca repetidas e duradouras relações de troca entre si e, ao mesmo tempo, não possuem a necessidade de uma autoridade organizacional para arbitrar e resolver conflitos que possam surgir durante as trocas. Ou seja, por meio das relações estabelecidas, é possível que a rede se mantenha ao longo do tempo, sem que haja o dever da estruturação de formas hierárquicas, por exemplo.

A base das redes interorganizacionais é cooperação entre os atores envolvidos, sendo reforçados assim os aspectos de confiança e da visão de longo prazo nas relações entre estes. Jarillo (1993) explica que o ganho oportunista pode ser facilmente percebido e alcançado, enquanto a perda futura (a retaliação pelo oportunismo) depende da existência de mais oportunidades de cooperar, então os envolvidos não irão trapacear se quiserem continuar a fazer negócios futuramente, mas, se não houver esse entendimento, a colaboração é mais dificilmente executada.

Neste aspecto, Gulati, Lavie e Madhavan (2011) apontam que são crescentes as pesquisas que sugerem que os laços de uma organização com outras organizações fornecem recursos que atribuem vários benefícios. Sendo que reforçar e nutrir laços com parceiros, isto é, adotar práticas colaborativas efetivas, é uma forma de acessar e integrar os recursos dos parceiros para a alavancagem de todos. Assim, a seguir, serão apresentadas informações sobre os ganhos que podem ser alcançados por meio da colaboração em rede.

\subsubsection{Ganhos coletivos}

As práticas colaborativas para mudanças nas formas de atuação dentro das organizações e também em suas redes externas, bem como a formação de novas parcerias surgem como uma forma de responder as mudanças sociais, ambientais e mercadológicas, ou seja, trata-se de uma necessidade de adaptação (Roome \& Louche, 2016). Além disto, observa-se que existe um conjunto de ganhos que podem alcançado por participantes de uma rede de cooperação pela execução das práticas colaborativas. Podolny e Page (1998) destacam como principais: aprendizagem, benefícios econômicos, legitimação e status e apresentam ainda uma categoria de "outros benefícios da forma de organização em rede".

No que diz respeito a aprendizagem, os mesmos autores dizem que esta pode ser acessada em razão da diversidade e da complexidade de rotinas que podem ser verificadas em uma rede de organizações. Neste sentido, Powell, Koput e Smith-Doerr (1996), em seu estudo sobre empresas de biotecnologia, afirmam que a aprendizagem ocorre justamente pelo pertencimento a uma comunidade, que pode apresentar diferentes tipos de organizações e práticas organizacionais. Muitos dos ganhos em termos de aprendizagem são consequências não previstas pelas organizações, pois o conhecimento é obtido pela colaboração em um projeto específico, mas esta participação tem resultados inesperados não aparentes no início do relacionamento, visto que é a aliança entre organizações que permite que a aprendizagem ocorra.

Já em relação a legitimação e status, Podolny e Page (1998) dizem que diversos estudos apontam para a relação que é feita entre a legitimidade e status de um ator que seja parceiro da rede 
e que impacta na "aquisição" de legitimidade e status que ocorre mediante a filiação de um novo parceiro à mesma rede. Neste caso, o ganho de legitimidade e status é adquirido pela credibilidade associada a outras organizações da rede ou a própria rede. Sydow e Windeler (1998) apontam que a legitimação da rede depende dos resultados obtidos pelos participantes, para os autores, ao passo que, com os participantes alcançando bons resultados, a rede ganha legitimação e está poderá impactar positivamente na imagem dos participantes. Desta forma, a legitimidade da rede pode influenciar nos resultados alcançados por seus participantes, ao mesmo tempo que participantes que alcançam bons resultados reforçam a legitimidade da rede como um todo, beneficiando também os demais integrantes.

No que se refere aos benefícios financeiros, pode-se dizer que estes se relacionam a redução de custos (inclusive os chamados custos de transação) e aumento da qualidade pela melhoria de relacionamentos, uma vez que, ao promover melhor comunicação, as organizações em rede facilitam uma maior coordenação ante mudanças, cujo significado não pode ser totalmente transmitido ou compreendido apenas por sinais de preços. Além dos benefícios financeiros, de aprendizagem e de legitimação e status vários outros ganhos podem ser obtidos pela adoção de práticas de colaboração (Podolny \& Page, 1998).

\section{MÉTODO}

Tendo em vista o objetivo proposto, bem como as características do objeto de estudo, optouse, neste estudo, pela abordagem qualitativa, que se propõe a analisar a interpretação que os indivíduos atribuem ao fenômeno a ser estudado (Merriam, 1998). Definiu-se a realização de um estudo de caso, que é uma estratégia de pesquisa que se visa compreender a dinâmica presente em determinada realidade com características únicas e que apresente relevância teórica ou para o contexto organizacional (Yin, 2005). Para tanto, o caso do Fórum de Recicladores do Vale dos Sinos (Frvs) foi escolhido por tratar-se de uma rede de organizações forjada de acordo dos princípios da Economia Solidária, que se diferenciam das empresas tradicionais, focadas no lucro. Esta rede apresenta características bastante peculiares, por tratar-se de pequenas organizações que têm seu foco na inclusão social por meio do trabalho e da geração de renda.

Para melhor entendimento do caso e verificação de adesão aos temas de interesse do estudo, iniciou-se a pesquisa com uma entrevista não-estruturada de, aproximadamente, 50 minutos e, posteriormente, foram realizadas mais seis entrevistas, até que se alcançasse a saturação dos resultados, tais entrevistas tiveram como base um roteiro semiestruturado, e duraram, em média, 45 minutos de duração. Foram escolhidos participantes da rede que tivessem, pelo menos, dois anos de participação, conforme descrição na figura a seguir.

\begin{tabular}{|c|l|c|}
\hline Identificação & \multicolumn{1}{|c|}{ Atuação na rede (FRVS) } & Tempo de atuação \\
\hline E1 & Entidade de Apoio & 02 anos \\
\hline E2 & Entidade de Apoio & 05 anos \\
\hline E3 & $\begin{array}{l}\text { Coordenação de atividades e atuação em um dos } \\
\text { EES integrantes }\end{array}$ & 14 anos (desde a fundação) \\
\hline E4 & $\begin{array}{l}\text { Coordenação de atividades e atuação em um dos } \\
\text { EES integrantes }\end{array}$ & 14 anos (desde a fundação) \\
\hline E5 & $\begin{array}{l}\text { Recicladora participante do Fórum e Comissões } \\
\text { de Trabalho }\end{array}$ & 04 anos \\
\hline E6 & $\begin{array}{l}\text { Presidente de um EES integrantes e Comissões de } \\
\text { Trabalho }\end{array}$ & 11 anos \\
\hline
\end{tabular}

Figura 1 - Identificação dos entrevistados

Fonte: elaborado pelos autores 
Além das entrevistas, foram realizadas observações em reuniões da rede e nas atividades de um dos empreendimentos participantes, totalizando, aproximadamente, 18 horas de observação. Para realização das entrevistas e da observação, foi criado roteiro com base em cinco categorias de análise: características do Frvs; aprendizagem por meio da rede (Podolny e Page, 1998; Hamel, 1991; Powell, Koput e Smith-Doerr, 1996); legitimação e status (Podolny e Page, 1998; Hamel, 1991; Sydow e Windeler, 1998); benefícios financeiros (Podolny e Page, 1998; Balestrin e Vargas, 2004); outros ganhos obtidos (Podolny e Page, 1998; Balestrin e Vargas, 2004).

Para análise dos dados, optou-se pela análise de conteúdo, que, segundo Lakatos e Markoni (1991), permite um grau de compreensão mais profundo, uma vez que possibilita descrever e interpretar a comunicação de maneira sistemática. Portanto, serão apresentados trechos das entrevistas na seção de Análise dos Resultados como evidência empírica. Para validação dos resultados obtidos, após a conclusão da pesquisa foi realizada uma apresentação em uma das reuniões dos integrantes da rede pesquisada. Na ocasião, 15 representantes estavam presentes e com as contribuições dos participantes foi possível confirmar as práticas de cooperação executadas e os ganhos alcançados. Utilizou-se ainda dados secundários como: documentos compartilhados pelo Fórum, postagens e vídeos disponibilizados em suas redes sociais e reportagens veiculadas sobre o Fórum dos anos de 2014, 2015 e 2016, totalizando 20 itens.

\section{APRESENTAÇÃO E ANÁLISE DOS RESULTADOS}

Para que exista um melhor entendimento da rede pesquisada, de suas práticas de colaboração, bem como dos ganhos gerados por estas, na apresentação e análise de resultados inicialmente são apresentadas informações sobre o Fórum de Recicladores do Vale dos Sinos e, na sequência, ganhos coletivos e práticas colaborativas que foram adotadas para tanto. Os dados são apresentados seguindo as categorias de análise previamente propostas.

\subsection{Fórum de Recicladores do Vale dos Sinos (Frvs)}

O Fórum de Recicladores do Vale dos Sinos (Frvs) surgiu, em 2002, quando recicladores perceberam a necessidade de construir um espaço para estabelecer ações conjuntas. O Frvs é composto por 17 EESs, identificados como associações e cooperativas de recicladores, oriundas de oito municípios do Vale dos Sinos, no Rio Grande do Sul, com 406 trabalhadores atualmente (210 mulheres e 196 homens). Desde sua fundação, conta com entidades de apoio como Universidades da região e, mais recentemente, de um Instituto Federal de Educação, mediante ações de suas incubadoras. Embora tais entidades de apoio tenham um papel importante para legitimação da rede, estas não exercem funções de governança, atuando apenas no aspecto consultivo aos integrantes da rede, sem poder de tomada de decisão pelo Fórum.

Para fortalecimento dos laços entre os EESs, são realizadas reuniões mensais abertas a participação dos interessados. As pautas das reuniões abertas são definidas em reunião prévia, também mensal, quando um grupo representativo do Frvs define os assuntos relevantes para a discussão em grupo. A definição dos temas a serem abordados é feita com base na análise das reuniões anteriores e das demandas levantadas pelos recicladores participantes durante o período. Esta prática direciona a reunião para as demandas emergentes e também contribui para inibir situações de oportunismo, uma vez que existe um planejamento e um acompanhamento das necessidades dos participantes.

Pode-se associar o Frvs a uma forma de rede apresentada por Todeva (2006), chamada de universal, em que todos os atores da rede estão conectados entre si, ou seja, cada ator da rede está conectado com todos os outros. Ainda que alguns sejam responsáveis por algumas funções mais específicas, que a seguir serão apresentadas, todas as decisões são compartilhadas e cada um tem direito a voto, com o mesmo peso. Desta forma, pode-se ainda propor a associação desta prática ao que foi apresentado por Provan e Kenis (2008), como governança participante, que é a rede 
governada por seus membros, sem uma entidade de governança específica ou separada. A governança nesta forma pode ser realizada de maneira formal; por meio de reuniões regulares de representantes de organizações designadas ou, até mesmo mais informalmente, pelos esforços do grupo.

Além dos aspectos diretamente ligados ao Frvs, destaca-se que, de acordo com o último relatório do Ipea (2016), no Brasil tem se instituído, nos últimos anos, uma série de atos normativos na forma de leis, decretos, portarias, regulamentos e normas sobre a gestão dos resíduos sólidos. Isto pode estar relacionado a pressão popular e das organizações sociais preocupadas com o meio ambiente e com a saúde humana. Esses atos normativos, incidem sobre todas as etapas que do processo de gestão dos resíduos sólidos passam a regular o comportamento dos atores envolvidos, o que afeta positivamente o Frvs.

Um exemplo disto, foi a promulgação em 2010, da Política Nacional de Resíduos Sólidos (Lei no 12.305, de 2 de agosto de 2010), após, aproximadamente, 20 anos de tramitação no Congresso Nacional. Uma das principais inovações trazidas pela referida lei foi a introdução do conceito de "responsabilidade compartilhada" pelo ciclo de vida dos produtos, que determina os deveres de todos envolvidos no processo de fabricação, descarte e reciclagem de resíduos. (Ipea, 2016). Para que possam ser obtidos benefícios desta maior organização e visibilidade da gestão de resíduos, faz-se necessário que os EESs se organizem e fortaleçam para conhecer e fazer valer seus direitos e obrigações. Desta forma, a seguir são apresentadas as práticas de colaboração do Frvs, bem como os benefícios percebidos por meio desta organização em rede.

\subsection{Aprendizagem}

Para Podolny e Page (1998), as redes oportunizam aprendizagem porque preservam maior diversidade de rotinas do que as hierarquias, ao mesmo tempo em que transmitem informações mais ricas e também mais complexas do que as relações de mercado. É interessante observar nesta rede questões que a tornam diferenciada por tratar-se de um ramo de atuação (reciclagem) ainda muito incipiente no que se refere ao acesso a informações e tecnologias, podendo ser considerada uma área que sofre de bastante precarização de formas de organização e métodos de trabalho. Também é associada a falta de qualificação profissional e conhecimento técnico em relação a resíduos (Santos et al., 2016).

De acordo com os mesmos autores, a criação de aprendizado em uma rede pode ocorrer mediante a transferência de "peças contentoras" de informação, fazendo com que, ao invés de facilitar a transferência de informações entre dois pontos ou "nós" da rede, a relação permanente de trocas na rede pode produzir novos conhecimentos, fazendo com que a rede passe a ser o local de inovação. Ou seja, a geração de conhecimento ocorre na rede e não mais pontualmente pelos atores que a compõem, ainda que a contagem de conexões reflita o conhecimento gerado na rede, pois, muitas vezes, não é claro o caminho do aprendizado na rede, quais são os canais para que o fluxo de informações aconteça.

Ao analisar os relatos dos participantes do Frvs, é possível observar que um dos ganhos percebidos se dá pelas práticas de troca de informações e conhecimento. Por meio das reuniões realizadas mensalmente é aberto espaço para que os participantes possam relatar situações problemáticas e ouvir opiniões de outros participantes, bem como também é aberto espaço para que as boas práticas realizadas em um EES sejam expostas a todos. Além disto, podem fazer uso de recursos externos para entendimento de situações novas ou adaptações.

O fórum é formativo e informativo, isso sempre foi uma bandeira do Fórum. (E1)

A gente vê o fórum como um local de formação, pela participação do fórum e troca de informação. (E3)

A troca de ideias no fórum é muito importante, é um espaço para isso. Daqui um pouco se vive uma situação que outros já revolveram. (E5) 
Como é possível observar nas falas dos entrevistados E1, E2, E3, a interação é uma prática muito importante para a geração da aprendizagem desta rede. Neste sentido, de acordo com Wegner (2011), a participação em atividades da rede é uma parte fundamental para a efetividade da aprendizagem. $\mathrm{O}$ ambiente da rede propicia a troca, uma vez que é livre de conflitos, por não haver concorrência, e por possuir objetivos comuns.

Embora o maior fluxo de informações aparentemente venha das trocas nas reuniões, também são elencadas pelos entrevistados práticas de aprendizado formal aos participantes, pela realização de cursos, em que as verbas normalmente são buscadas em conjunto. Recentemente, o grupo realizou uma série de capacitações, com recursos adquiridos por edital de uma entidade de incentivo à pesquisa e desenvolvimento. Estas formações foram direcionadas à dicção e oratória para mulheres, inclusão digital e à correta triagem, classificação e análise de qualidade de resíduos.

Tais ações parecem ter causado um impacto positivo no grupo. Nas observações, foram apontados depoimentos de vários participantes sobre as mudanças que já estavam ocorrendo no ambiente de trabalho em razão de novos conhecimentos adquiridos, como melhor organização e controle - por meio da criação de planilhas, que oportunizam inclusive a comparações entre os EES - e a maior contribuição das mulheres nas discussões e demandas diárias. A importância das capacitações também é evidenciada pelos entrevistados a seguir.

Tem a aprendizagem mais formal, tipo esses cursos de informática, mas a maior aprendizagem acho que vem das trocas em que cada um apresenta as situações dos municípios e recebe informações para outras. (E1)

Tem uma preocupação ali de capacitar o grupo, a questão das mulheres (Dicção e oratória para mulheres) [...] teve um resultado. Claro que todas elas participaram também do curso de informática, dos intercâmbios, se inseriram. Uma vontade também é que metade do tempo das reuniões seja de formação com alguém de fora, fazendo uma fala. (E2)

Os cursos realizados pelo Fórum, sem o Fórum não teríamos as parcerias necessárias para conseguir. Daqui um pouco, as cooperativas vão crescer e vamos precisar de pessoas qualificadas. (E4)

Uma ação que merece destaque no que se refere a aprendizagem é a adoção de "intercâmbios" pelo Frvs, percebidos como uma forma de conhecer a realidade dos EESs parceiros e auxiliar os participantes na melhora de práticas e geração de ideias. O trabalho ocorreu em duas etapas, num primeiro momento grupos (trios ou duplas representantes de cada EES) visitaram o local de trabalho de outros participantes. No final da visitação, foram realizadas reuniões de fechamento em que cada visitante pode expor suas opiniões, tirar dúvidas e fazer sugestões, num segundo momento estes representantes foram trabalhar em outros EESs, vivenciando a rotina de trabalho, as diferenças e as demandas de um local diferente do seu.

Podolny e Page (1998) sugerem que as práticas de trocas entre "peças" da rede facilitem não só a transferência de conhecimentos existentes, mas a geração de novos. De acordo com os relatos obtidos na reunião Frvs, essa prática foi muito rica para a rede, por oportunizar às pessoas a troca de lugares, de ambientes, ver formas diferentes de trabalho e diferentes dificuldades enfrentadas entre os municípios. Por exemplo, alguns possuem coleta seletiva, outros não, alguns têm falta de determinados materiais, alguns têm melhor estrutura física, etc. Nas entrevistas realizadas, esta ação também foi pontuada.

Um trabalhou na cooperativa do outro. Primeiro, foi visitar e conhecer os processos [...] depois teve de trabalhar mesmo, dois de cada trocaram e foram trabalhar em outra, intercâmbio mesmo. Eles aprendem muita coisa, porque cada cooperativa tem seu jeito de fazer. $(\mathrm{E} 1)$

Fizemos roteiros para ir trabalhar em outras cooperativas, ver como fazem a separação, como vendem. Foi uma oportunidade de trabalhar no lugar do outro, levar e dar ideias, saber o que estão passando. (E5) 
Uma outra prática de colaboração adotada pelo Frvs, foi a criação de grupos de trabalho direcionados para certos objetivos e demandas atuais. Esta prática também aparece como resposta aos desafios enfrentadas pelo grupo, tais como a dificuldade de comercialização em rede, a falta de registros e a necessidade de meios de comunicação mais ágeis entre todos os integrantes, por exemplo. Estas pequenas comissões são formadas por um representante de alguma das entidades de apoio e por representantes do Fórum que se identificam com cada temática, e, atualmente, estão divididas em: Redes de Comercialização, Comunicação e Registro e Formação e Capacitação. A partir disto, buscam-se informações, planejam-se ações e redistribuem-se tais informações ao grande grupo. Esta proposta é uma forma de direcionar as pessoas mais interessadas em determinado assunto a contribuir para o fluxo de informações e a busca de objetivos do Fórum.

Uma das comissões é a ideia de comercializarem juntos, um dos desafios é a padronização de processos. (E1)

Além disso, [...] tentar fomentar a comunicação e registro, porque existe dificuldade de trocar se não for nas reuniões, por exemplo, grupo de whats up funciona. (E1)

Agora nós inserimos as entidades de apoio (nas comissões) [...]. Mas o papel é de orientar o coordenador e não fazer por eles e respeitar o que eles querem fazer e não o que tu achas que deve ser feito, entender o momento de trazer as ideias. (E2)

Como se pode observar no relato, estas Entidades de Apoio desempenham um papel importante no sentido de orientar e, até mesmo, de ajudar a desenvolver lideranças. Esse processo também acaba por contribuir não somente para a rede como um todo, mas para o desenvolvimento profissional das pessoas diretamente envolvidas de cada um dos EESs. Para Hamel (1991), a colaboração proporciona a oportunidade para que um parceiro possa internalizar as habilidades dos outros pelas trocas e, assim, melhorar a sua posição tanto dentro como fora da relação estabelecida.

Com o tempo esses associados passam a assumir responsabilidade dentro do fórum, agora temos uma equipe para comercialização, que é para troca com este fórum, temos dois associados nesta equipe. E3

Nas entrevistas, é possível observar que, ao mesmo tempo que a aprendizagem é um objetivo da rede, também é um fator que motiva a permanência na rede, pois é percebida como um ganho que tem impacto em diversos outros aspectos de cada uma das cooperativas, como na melhoria de seus processos, por exemplo. Neste sentido, Wegner (2011) ainda destaca que, em seu estudo realizado em redes de pequenas empresas, a aprendizagem é um fator de motivação para a participação, bem como da manutenção do interesse nas práticas de colaboração.

Para os entrevistados que participaram da fundação do Fórum, as mudanças nos EESs participantes são visíveis, assim como as demandas do grupo também evoluíram. Atualmente, a maioria dos EES possui contratos de coleta seletiva, por exemplo, sendo a busca por contratações uma de suas principais lutas até alguns anos atrás. Em razão desta evolução é que já é possível pensar em outras necessidades, tais como a formação dos recicladores, a melhora da comunicação e registros e a possibilidade de uma rede de comercialização.

Esta mudança de objetivos também reforça a aprendizagem da rede como um todo, uma vez que pelas trocas foi possível colocar em prática as boas ações realizadas em outros EESs. O fluxo de informações dentro do Frvs é apresentado como um dos fatores de grande importância para seu desenvolvimento e continuidade. É importante ressaltar que, para Knight e Pye (2005), a aprendizagem pode ocorrer no nível da rede e não apenas de forma pontual nas organizações, seja por meio de práticas, formas de interpretação ou mesmo estrutura da rede.

Tais práticas auxiliam na mitigação de problemas como os relatados por Santos et al. (2016) em relação à necessidade de qualificação dos trabalhadores de reciclagem, bem como a necessidade de conhecimento quanto aos materiais e processos para atendimento às demandas do mercado. Como forma de síntese, a Figura 2 lista as práticas associadas a esta categoria de análise. 


\begin{tabular}{|c|l|l|}
\hline Categoria & \multicolumn{1}{|c|}{$\begin{array}{c}\text { Principais práticas } \\
\text { colaborativas identificadas }\end{array}$} & \multicolumn{1}{c|}{ Ganhos associados } \\
\hline \multirow{4}{*}{ Aprendizagem } & $\begin{array}{l}\text { Reuniões periódicas e encontros } \\
\text { diversos (conforme } \\
\text { necessidade) }\end{array}$ & $\begin{array}{l}\text { Obtenção de informações, acesso a } \\
\text { solução de problemas, aconselhamentos } \\
\text { para enfrentamento de situações }\end{array}$ \\
\cline { 2 - 3 } & $\begin{array}{l}\text { Capacitações em cursos e } \\
\text { formaços através da rede }\end{array}$ & $\begin{array}{l}\text { Melhora de conhecimentos e habilidades } \\
\text { dos integrantes da rede tanto para } \\
\text { execução de suas atividades atuais, quanto } \\
\text { para desempenho de novas }\end{array}$ \\
\cline { 2 - 3 } & "Intercâmbios" entre EES & $\begin{array}{l}\text { Fluxo de informações na rede, melhoria de } \\
\text { processos }\end{array}$ \\
\cline { 2 - 3 } & $\begin{array}{l}\text { Grupos de trabalho para busca } \\
\text { direcionada de conhecimento, } \\
\text { conforme objetivos da rede }\end{array}$ & $\begin{array}{l}\text { Preparação para viabilização de objetivos } \\
\text { estratégicos da rede }\end{array}$ \\
\hline
\end{tabular}

Figura 2 - Práticas colaborativas e ganhos associados à aprendizagem

Fonte: Elaborado pelos autores

\subsection{Legitimação e status}

Podolny e Page (1998) alegam que se um parceiro da rede possui legitimidade ou status considerável, o ator que estiver conectado a este poderá derivar desta legitimidade ou status a partir de sua filiação. $\mathrm{O}$ alcance destes fatores, poderá, por sua vez, incorrer em uma série de benefícios econômicos positivos para o novo integrante, benefícios estes que vão desde a sobrevivência até o impacto no crescimento organizacional ou no aumento de rentabilidade.

No caso dos EES da reciclagem, a legitimação torna-se de grande importância para sua sustentabilidade em longo prazo, uma vez que, de acordo com Rodrigues e Ichikawa (2015), a sociedade é discriminatória com os trabalhadores deste ramo, que também sofrem com mecanismos de fiscalizações autoritários de órgãos como a prefeitura da cidade de atuação.

Mais do que atuar no sentido de dar legitimidade aos EES participantes, conforme relatado em entrevistas, o Frvs reforça a legitimidade da classe de trabalhadores (recicladores) associados a estes EESs. Além disto, embora possam passar por adversidades, tal como pressões por parte dos compradores ou mesmo risco de diminuição da demanda atendida, em função de questões políticas - como possibilidade da coleta automatizada de resíduos, por exemplo - os entrevistados percebem a "força" do Frvs em vários momentos. Seja em uma negociação com o poder público, com empresas privadas ou mesmo para garantir que o que está acordado em contrato seja cumprido, o poder do grupo e a atuação em rede tendem a minimizar as dificuldades encontradas.

Ter um Fórum já passa toda uma credibilidade perante a um gestor público e perante a sociedade. Essa junção com as entidades de apoio também fortalece o reconhecimento. (E1) Os benefícios estão muito relacionados a força coletiva que esse espaço se propõe a constituir por parte do coletivo do Fórum. Então não é a cooperativa A B, C, é o Fórum se colocando. (E2)

Para Hamel (1991), os conhecimentos absorvidos nas trocas entre parceiros podem impactar em outros aspectos de cada organização envolvida, como o seu poder de barganha, por exemplo. No caso do Frvs, observam-se ganhos no poder de negociação junto as prefeituras e empresas contratantes, visto que pelo fortalecimento, resultante da união do grupo, bem como pelo aprendizado sobre formas de negociar e sobre como sobre os direitos dos EES, existem mais possibilidades de acordar com os contratantes.

Nos juntamos e mostramos a importância do nosso trabalho[...], hoje já conseguimos colocar para o poder público o que precisamos. (E3)

Revista de Gestão Social e Ambiental - RGSA, São Paulo, v. 11, n. 3, p. 37-55, set./dez. 2017. 
Numa negociação com o poder público, isso tem um peso enorme. Quando tu colocas para um prefeito isso, são mais de 400 pessoas. O Fórum tem muita força. (E6)

Uma das práticas colaborativas visíveis no Frvs é a reciprocidade. Em algumas falas de entrevistados, são colocadas situações que remetem as relações de confiança quando afirmam que todos ajudam ou que já ajudaram e hoje estão recebendo ajuda. Então, se um do EES necessita do apoio desta rede, ele recebe e, ao mesmo tempo, se dispõe a ajudar e compartilhar soluções se outro ente precisar. Para Jarillo (1993), a cooperação pode ser desenvolvida pela perspectiva de longo prazo e da confiança estabelecida mediante a repetição de relações positivas. Neste caso, é possível perceber a importância desta continuidade nas relações estabelecidas.

Eu vejo que o meu grupo pode contribuir com outro, assim como eu recebo contribuições. (E3)

Nunca se negam a participar e ajudar, já tivemos manifestações contra a incineração, agora foi feita uma carta em nome do Fórum para a contraproposta em cidade $X$. O Fórum se articula para tomar ações conjuntas em prol das cooperativas. Esse é o foco do Fórum: fortalecer a nossa categoria. (E4)

Mesmo que seja necessário investimento de tempo "voluntário" de algumas pessoas ou, de certa forma, custeado pelos EESs, são apontados ganhos na participação e nos investimentos realizados nas ações do Fórum, ficando a expectativa da possibilidade de ganhos futuros em novas necessidades de cooperar, este aspecto pode se relacionar ao já citado Jarillo (1993). Além da perspectiva de ganhos futuros, também se torna evidente a preocupação com o fortalecimento de toda a rede. Pode-se confirmar isto no relato a seguir.

Tudo tem custo, tem pessoas, planejamento, nosso papel é ajudar, ser solidário e sabemos que esse benefício depois retorna para nós. Isso é economia solidária. Quando um grupo está ruim, todos estão. (E4)

Em concordância com as práticas adotadas pelo Frvs, pode-se citar Sydow e Windeler (1998) que apontam que a eficácia de resultados da rede deve ser entendida como um resultado e, ao mesmo tempo, como um meio de práticas interorganizacionais, estabelecidas em dois níveis de análise: no nível individual e no nível da rede. O primeiro nível, ou individual, pode ser evidenciado quando uma organização particular é capaz de se apropriar e, eventualmente, utilizar no seu ramo de atuação a efetividade, os resultados da rede em seu favor. Já no nível da rede, a efetividade é afetada pelos resultados individuais de seus integrantes, sendo que a rede poderá fazer concessões para melhora destes resultados, uma vez que sua manutenção também depende disto.

A legitimação, segundo os mesmos autores, se fortalece pelo estabelecimento das normas de significação, que dão sentido a existência da rede e por meio do sucesso obtido (como os ganhos gerados, por exemplo) é que esta legitimação da rede ocorre. Desta forma, observa-se que, ao mesmo tempo em que a legitimação da rede pode afetar os resultados dos participantes, os bons resultados gerados na rede fazem com que esta validação retorne e mais uma vez fortaleça a rede. $\mathrm{Na}$ figura, a seguir, apresenta-se resumo das principais práticas associadas a esta categoria de análise. 


\begin{tabular}{|c|l|l|}
\hline Categoria & \multicolumn{1}{|c|}{$\begin{array}{c}\text { Principais práticas } \\
\text { colaborativas identificadas }\end{array}$} & \multicolumn{1}{c|}{ Ganhos associados } \\
\hline \multirow{2}{*}{$\begin{array}{c}\text { Legitimação e } \\
\text { status }\end{array}$} & $\begin{array}{l}\text { Mobilizações em favor de } \\
\text { integrantes da rede }\end{array}$ & $\begin{array}{l}\text { Fortalecimento da classe, melhora do } \\
\text { poder de barganha }\end{array}$ \\
\cline { 2 - 3 } & $\begin{array}{l}\text { Uso do nome da rede em } \\
\text { negociações }\end{array}$ & $\begin{array}{l}\text { Maior poder de barganha, mais segurança } \\
\text { para negociação }\end{array}$ \\
participantes da rede & $\begin{array}{l}\text { Fortalecimento da rede e dos EES } \\
\text { individualmente (ajudam-se para alcançar } \\
\text { objetivos que não conseguiriam sozinhos) } \\
\text { e reforço da confiança para necessidades } \\
\text { futuras }\end{array}$ \\
\hline
\end{tabular}

Figura 3 - Práticas colaborativas e ganhos associados à legitimação e status Fonte: Elaborado pelos autores

\subsection{Benefícios financeiros}

Conforme exposto anteriormente, os benefícios financeiros advindos da participação em uma rede, podem ser representados de várias formas. Ao promover uma maior comunicação do que as demais relações de mercado, as formas de organização em rede facilitam uma maior coordenação em face de mudanças, cujo significado não pode ser totalmente compreendido por meio de sinais de preços. Além disto, é necessário observar os benefícios financeiros relacionados a custos e melhoria de qualidade (Podolny \& Page, 1998).

Os ganhos financeiros adquiridos no Frvs, estão normalmente relacionados aos demais benefícios. Pela legitimidade da rede, construída a partir do fortalecimento do grupo e de sua atuação junto ao poder público e mesmo de empresas privadas, foi possível a realização de contratos que garantem maior segurança financeira e planejamento de longo prazo aos EES. Outra situação é relativa às formações que, via Fórum, possibilitaram a obtenção de recurso financeiro para realização, mesmo a legitimidade e o apoio para EES inscreverem-se em editais, e terem acesso a recursos para compra de maquinários ou ainda a troca de informações que ajuda no momento de negociação de preço de venda junto a compradores, como é possível observar nos relatos seguintes.

$\mathrm{O}$ retorno financeiro vem por todas as coisas anteriores. Quando alguns municípios tinham a coleta paga e outros não, a gente fazia seminários e chamava o prefeito para vir e saber como era nos outros. Agora eles trocam muito para quem eles vendem, que é nosso próximo passo é vender juntos, como em outras cooperativas no país que já trabalham em rede, mas só essas trocas já ajudam muito, porque isso impacta na remuneração deles. (E1) Nós conseguimos articular a compra de equipamentos para beneficiamento dos materiais por meio do apoio do Fórum para projetos e parcerias e fomos abrindo os horizontes, hoje fazemos o beneficiamento. (E4)

A compra do caminhão e de equipamentos já que foram projetos ganhos pelo Fórum ou com ajuda do Fórum. (E6)

Eles se dão conta, que economicamente sozinhos, não vão vencer, vencer que eu digo é transpor essa relação que eles têm hoje com os compradores que é quem fica com o maior ganho financeiro. (E2)

Um fator interessante é o uso da rede para articular a possibilidade de comercialização conjunta e o uso das estruturas dos empreendimentos parceiros para fazer diferentes partes do processo e alcançar maior volume de produção. Este poderá ser um ganho para os envolvidos, uma vez que é possível assim gerar valor agregado em seu processo, além de melhorar seu poder de barganha por não depender apenas de intermediários, melhorando também o preço de venda e o retorno para os associados. Entende-se que, para os EESs, que compõem esta rede, as oportunidades de fortalecimento são importantes, pois, por tratarem-se de pequenos empreendimentos, isoladamente possuem menor poder de negociação. 
Além disto, como observado nas práticas relatadas anteriormente, existem ganhos relacionados à melhoria de produtividade e de métodos de trabalho em razão da aprendizagem que ocorre por estarem na rede do Fórum. Neste sentido, Balestrin e Vargas (2004), em estudo realizado em uma rede de pequenas e médias empresas, apontam, além de impactos em aprendizagem e comportamento, os impactos econômicos gerados pela interação em rede em atividades relacionadas a comercialização de produtos, a melhoria de processos de produção, a melhor negociação de preços junto a compradores, acesso ao fornecimento de crédito, a obtenção de economias de escala, escopo e especialização, entre outros.

Bortoli (2009) destaca como uma das adversidades dos trabalhadores da reciclagem a baixa remuneração. Neste sentido, as práticas elencadas na pesquisa demonstram formas encontradas pelo Frvs de melhorar seus ganhos diretos (contratos e negociações) e indiretos (melhoria de processos), conforme síntese apresentada na Figura 4.

\begin{tabular}{|c|l|l|}
\hline Categoria & \multicolumn{1}{|c|}{$\begin{array}{c}\text { Principais práticas } \\
\text { colaborativas identificadas }\end{array}$} & \multicolumn{1}{c|}{ Ganhos associados } \\
\hline \multirow{2}{*}{$\begin{array}{l}\text { Benefíçocios em nome do } \\
\text { fórum, manifestações, troca de } \\
\text { informações entre participantes } \\
\text { fobre práticas e legislação } \\
\text { vigente }\end{array}$} & $\begin{array}{l}\text { Contratos firmados com instituições } \\
\text { públicas e empresas, assegurando durante } \\
\text { a vigência materiais e rendimentos } \\
\text { mensais. }\end{array}$ \\
\cline { 2 - 3 } & $\begin{array}{l}\text { Busca de editais em conjunto e, } \\
\text { através da troca de informações, } \\
\text { auxílio para submissão de } \\
\text { projetos }\end{array}$ & Compra de equipamentos e maquinários \\
\cline { 2 - 3 } & $\begin{array}{l}\text { Troca de informações sobre } \\
\text { oportunidades e novos } \\
\text { compradores }\end{array}$ & $\begin{array}{l}\text { Poder de barganha junto a intermediários } \\
\text { do processo de venda }\end{array}$ \\
\hline
\end{tabular}

Figura 4 - Práticas colaborativas e ganhos associados aos benefícios financeiros Fonte: Elaborado pelos autores

\subsection{Outros benefícios gerados na rede}

Perrow (1993) identifica uma série de benefícios de bem-estar social, no que se refere a redes de pequenas empresas, ou redes de pequenos produtores. Para o autor, em comparação com organizações maiores ou mais burocráticas, as pequenas redes de empresas facilitam aos indivíduos maior autonomia, além de conduzirem a uma menor desigualdade na distribuição da riqueza, e fomentar um maior senso de comunidade (como citado em Podolny e Page, 1998). Estes aspectos estão diretamente relacionados aos objetivos do Frvs. Por ser formado por EES de economia solidária, é perceptível uma grande preocupação dos participantes em fortalecer a solidariedade e cooperação, melhorando os benefícios e a remuneração gerados para todos os associados. Como a gestão dos EES é autogestionária, a autonomia é fortalecida nas tomadas de decisões e, que todos têm voto e voz, assim como ocorre no Fórum, mas respeitando e valorizando a importância da coletividade, que é o que fortalece o grupo.

Além disto, Balestrin e Vargas (2004) apontam como um dos resultados de seu estudo o impacto no comportamento dos participantes, percebido em razão de existir um espírito coletivo entre os envolvidos, que se torna fundamental para a existência de cooperação. No Frvs, este posicionamento é perceptível, tanto pela disposição para colaborar, que é muito presente nas falas dos entrevistados, quanto nos posicionamentos tomados durante a reunião plenária, onde são apresentadas mudanças de comportamento dos indivíduos que se relacionam à qualidade de vida, como, por exemplo, a organização do trabalho possibilitando diminuir a necessidade de horas excedentes de trabalho e aumentar o período reservado para descanso e lazer com a família. 
Bhatt e Altinay (2013) destacam que o capital social (conceito amplamente utilizado para se referir aos benefícios decorrentes de relações sociais entre indivíduos), pode auxiliar no sucesso das organizações voltadas a atender demandas sociais. Para os autores, por meio das redes sociais, recursos podem mais facilmente ser acessados, ou seja, restrições de acesso à recursos podem ser superadas, mobilizando outras formas de capital, que, por sua vez, facilitarão a confiança e a cooperação. Esta associação também é perceptível no Frvs, pois a reciprocidade entre os EES participantes, assim como a facilitação de acesso a informações e recursos advém principalmente das relações sociais forjadas na rede, além disto existem ganhos relacionados a convivência e qualidade de vida que impactam na vida pessoal dos indivíduos participantes,

No artigo que aborda as possíveis categorias de ganhos da atuação em rede, Podolny e Page (1998) chamam de outros "Outros benefícios" uma categoria genérica para tratar dos ganhos que não se inserem nas três categorias anteriores. Neste estudo, fica evidenciado que, no contexto de uma rede de EES, uma categoria importante é o empoderamento dos indivíduos participantes da rede. Pela coleta de dados, é possível inferir que os benefícios alcançados pelas práticas colaborativas extrapolam os benefícios financeiros, de legitimação da rede ou de aprendizagem. Isto é perceptível, pois, por meio destes benefícios, os indivíduos da rede são afetados diretamente no que se refere a inclusão social pelo trabalho e pela renda, do orgulho que passam a ter pelo pertencimento a rede e a uma classe de trabalhadores.

Desta maneira, a inclusão econômica, fortalecida e melhoradas pelas práticas de colaboração da rede, acaba por se fundir com os benefícios sociais que são alcançados pelos indivíduos do grupo. Como forma de síntese, a seguir, apresenta-se a Figura 5, que resume as principais práticas de colaboração desta rede referentes à categoria de análise "outros benefícios gerados pela rede".

\begin{tabular}{|c|l|l|}
\hline Categoria & \multicolumn{1}{|c|}{$\begin{array}{c}\text { Principais práticas } \\
\text { colaborativas identificadas }\end{array}$} & \multicolumn{1}{c|}{ Ganhos associados } \\
\hline $\begin{array}{c}\text { Outros } \\
\text { benefícios } \\
\text { percebidos }\end{array}$ & Consulta às entidades de apoio & $\begin{array}{l}\text { Orientações e sugestões para práticas } \\
\text { diversas }\end{array}$ \\
\cline { 2 - 3 } & Pertencimento ao grupo & $\begin{array}{l}\text { Benefícios sociais relacionados ao } \\
\text { desenvolvimento e autonomia dos } \\
\text { indivíduos participantes }\end{array}$ \\
\hline
\end{tabular}

Figura 5 - Práticas colaborativas e ganhos associados a outros benefícios

Fonte: Elaborado pelos autores

\section{CONSIDERAÇÕES FINAIS}

Este estudo teve por objetivo identificar as principais práticas colaborativas utilizadas por uma rede formada por Empreendimentos de Economia Solidária para a geração de ganhos coletivos. Na pesquisa realizada, foram obtidos resultados que demonstram a relação entre a adoção de uma série de práticas colaborativas (reuniões, troca de ideias e informações, projetos compartilhados, busca de recursos em editais para formação e compra de equipamentos, etc.) e ganhos ou impactos positivos gerados, tanto para os integrantes, como para a rede como um todo, o que se explicita pela evolução e pelas mudanças de objetivos propostos para o Frvs.

As categorias propostas por Podolny e Page (1998) como ganhos das redes podem ser visualizadas neste estudo de caso. Verificou-se que as práticas como as reuniões e os encontros, as capacitações, os grupos de estudos direcionados, assim como os intercâmbios entre EESs favorecem o ganho da aprendizagem e sendo destacado pelos entrevistados que as formações oportunizadas e, principalmente, as trocas geradas impactam em melhores formas de trabalhar e na obtenção de resultados superiores. Mediante práticas como sua apresentação enquanto FRVS, bem como de ações de manifestação junto ao poder público, entende-se que o Frvs alcança legitimidade, que, por sua vez, é apontada pelos entrevistados como um dos fatores que originou a formação da rede e que 
hoje apresenta resultados no sentido de fortalecimento da classe dos EESs participantes e influencia, inclusive no seu poder de barganha junto aos contratantes.

Tidos principalmente com um reflexo dos demais ganhos, os benefícios econômicos da rede também podem ser percebidos. Assim, a partir do momento em que a aprendizagem é internalizada pelos EESs, seus processos são melhorados ou ainda, a partir da legitimação da rede é possível conseguir melhores negociações de contratações e benefícios por meio de projetos.

Além disso, outros benefícios, tal como o empoderamento, são percebidos por meio das práticas de colaboração que se revelam a partir dos ganhos gerados para os indivíduos, no sentido de orgulharem-se do trabalho que executam, algo que é fortalecido nas reuniões do Frvs, bem como nas formações. A melhoria de condições de trabalho, pelo estabelecimento das trocas da rede e da manutenção da convicção de solidariedade e cooperação, também são caminhos para melhoria de desempenho.

Infere-se, assim, que os ganhos mencionados da organização em rede, por parte dos EESs que compõem o Frvs, impactam no enfrentamento de alguns dos principais desafios dos trabalhadores de reciclagem, tais como a baixa remuneração, a discriminação social, a dependência e fragilidade frente a outros atores da cadeia da reciclagem (Rodrigues \& Ichikawa, 2015), assim como a necessidade de conhecimento técnico no que se refere aos materiais coletados (Santos et al., 2016), bem como a dificuldade de formação de vínculos e continuidade de práticas (Bortoli, 2009).

Os benefícios sociais podem ser percebidos pelo que foi exposto pelos participantes, principalmente quando se referem aos avanços que obtiveram nas formações e trocas de informações da rede, bem como em relação ao fortalecimento da classe dos recicladores. Além destes benefícios, outro aspecto que é um diferencial para a rede é o acesso as entidades de apoio, o que lhes diferencia de outras redes, embora estas entidades tenham um papel de certa forma consultivo - o que também pode ser observado em redes, como as de fornecimento, por exemplo em Wilhelm (2011) - acabam agindo também como orientadores, na busca de novas parcerias e informações para o FRVS.

Estes apontamentos são válidos principalmente para reforçar a importância das práticas colaborativas como uma forma de fortalecimento da rede. Neste caso, em especial, que se refere a EES, que já tem em sua formação básica a colaboração entre indivíduos como esteio, mas que, por vezes, tem poucos acessos a recursos, como é o caso dos recicladores, torna-se ainda mais importante destacar de que formas a cooperação pode acontecer e como isso pode se refletir em ganhos para os envolvidos. A força do Frvs, destacada por alguns entrevistados, é fruto da colaboração e do esforço dos participantes para manutenção do vínculo, sem o qual muitos benefícios não seriam acessados.

A principal contribuição teórica desse estudo consiste em confirmar a relação positiva entre as práticas colaborativas utilizadas em redes de empreendimentos da economia solidária e as categorias de ganhos apresentadas na literatura, como aprendizagem (Podolny e Page, 1998; Hamel, 1991; Powell, Koput e Smith-Doerr, 1996), legitimidade e status (Podolny e Page, 1998; Hamel, 1991; Sydow e Windeler, 1998), ganhos econômicos (Podolny e Page, 1998; Balestrin e Vargas, 2004) e outros ganhos obtidos (Podolny e Page, 1998; Balestrin e Vargas, 2004). Para esta última categoria, destacamos no caso estudado o empoderamento dos indivíduos. A contribuição gerencial do estudo consiste em descrever um conjunto de práticas que podem ser utilizadas por outros EESs operando em rede para obtenção de melhores resultados.

A rede estudada possui particularidades, especialmente por suas características de respeito aos princípios de cooperação e solidarismo oriundos da economia solidária. No que se refere a governança, a autogestão que ocorre nos EESs participantes, também ocorre no Frvs e desta forma a rede se organiza e busca seus objetivos em conjunto há mais de 14 anos. Por esta razão, acredita-se que possam ser explorados com maior profundidade em pesquisas futuras os aspectos da governança em redes formadas por EES. 


\section{REFERÊNCIAS}

Balestrin, A., Vargas, L. (2004) A dimensão estratégica das redes horizontais de PMEs: teorizações e evidência. Revista de Administração Contemporânea. Curitiba, 8 (Ed. Especial), 203-228.

Bhatt, P., Altinay, L. (2013) How social capital is leveraged in social innovations under resource constraints? Management Decision, 51(9), 1772-1792.

Bortoli, M. A. (2009) Catadores de materiais recicláveis: a construção de novos sujeitos políticos. Revista Katálysis, 12(1), 105-114.

Castells, M. (1999) A sociedade em rede. São Paulo: (6ª ed.) Paz e Terra.

Cattani, A. D., Laville, J. L., Gaiger, L. I., \& Hespanha, P. (2009) Dicionário internacional da outra economia.

Coelho, D., Godoy, A. (2011) Entre latas, papelões e outros recicláveis: um estudo sobre a aprendizagem em empreendimentos solidários. In: Claudia S.A., Arida S.G. (Org.). Aprendizagem organizacional no Brasil. Porto Alegre: Bookman, 537-564.

Conselho Nacional de Economia Solidária (2015) $1^{o}$. Plano Nacional de Economia Solidária. Recuperado em: 16 agosto 2016, de:

<http://trabalho.gov.br/images/Documentos/EconomiaSolidaria/Plano NacionalEcoSol.pdf >.

Gaiger, L. I. (1998) A solidariedade como alternativa econômica para os pobres. Contexto e Educação, 13 (50), 47-71.

Gaiger, L. I. (2015) A economia solidária na marcha contra a pobreza. Sociologia, problemas e práticas, 79, 43-63.

Godoy, A. (2008). In: Hanashiro, D., Teixeira, M.Ll., Zaccarelli, L. (Org.). Gestão do fator humano: uma visão baseada nos stakeholders. (2. ed.) São Paulo: Saraiva.

Gulati, R., Lavie, D., Madhavan, R. (2011) How do networks matter? The performance effects of interorganizational networks. Research in Organizational Behavior, 31, $207-224$.

Hamel, G. (1991) Competition for competence and interpartner learning within international strategic alliances. Strategic Management Journal. 12(1 991), 83-103.

Ipea (2016) Catadores de materiais recicláveis: um encontro nacional. Recuperado em: 07 julho 2016, de:

<http://www.ipea.gov.br/portal/index.php?option=com_content\&view=article\&id=27461 >. Acesso em 07 de julho de 2016

Jarillo, C. (1993) Strategic networks. Oxford: Butterworth-Heinemann.

Knight, L., Pye, A. (2005) Network learning: an empirically derived model of learning by groups of organizations. Human Relations, 58 (3), 369-392.

Lakatos, E., Markoni, M. (1991) Fundamentos da metodologia científica. (3. ed.) Atlas. 
Laville, J. (2000) The third sector: a subject of study for economic sociology. Sociologie du Travail, 42 (4), 531-550.

Merriam, S. (1998) Qualitative research and case study applications in education. San Francisco: Jossey-Bass.

Podolny, J. M., \& Page, K. L. (1998) Network forms of organization. Annual Reviews Sociological, 24, 57-76.

Powell, W. W., Koput, K. W., \& Smith-Doerr, L. (1996) Interorganizational collaboration and the locus of innovation: networks of learning in biotechnology. Administrative Science Quarterly, 41(1), 116-145.

Provan, K. G., Kenis, P. (2008) Modes of network governance: structure, management, and effectiveness. Journal of Public Administration Research and Theory, 18(2), 229-252.

Raab, J., Kenis, P. (2009) Heading toward a society of networks: empirical developments and theoretical challenges. Journal of Management Inquiry, 198-210. April.

Rodrigues, F. S., Ichikawa, E.Y. (2015) O cotidiano de um catador de material reciclável: a cidade sob o olhar do homem ordinário. Revista de Gestão Social e Ambiental, 9(1), 97-112.

Roome, N., Louche, C. (2016) Journeying toward business models for sustainability : a conceptual model found inside the black box of organisational transformation. Organization \& Environment, 29(1), 11-35.

Santos, F. F. et al. (2016) Atores da cadeia de reciclagem: influência e impactos na atividade de triagem de materiais em uma cooperativa de sorocaba-sp. Revista de Gestao Social e Ambiental, $10(3), 85-101$.

Sies. (2013) Atlas Digital da Economia Solidária. Disponível em < http://sies.ecosol.org.br/atlas >. Acesso em 16 de ago. 2016.

Silverman, B. \& Baum, J. (2002) Alliance-based competitive dynamics. Academy of Management Journal, 45 (4), 791-806.

Singer, P. (2002) Introdução à economia solidária. São Paulo: Editora Fundação Perseu Abramo.

Sydow, J., Windeler, A. (1998) Organizing and evaluating interfirm networks: a structurationist perspective on network processes and effectiveness. Organization Science, 9 (3), 265-284.

Todeva, E. (2006) Business networks: strategy and structure. London: Toutledge.

Wegner, D. (2011) Aprendizagem interoganizacional: um estudo das redes horizontais de pequenas empresas. In: Antonello, C.S., Godoy, A.S. (Org.). Aprendizagem organizacional no Brasil. Porto Alegre: Bookman, 537-564.

Wilhelm, M. M. (2011) Managing coopetition through horizontal supply chain relations : linking dyadic and network levels of analysis. Journal of Operations Management, 29 (7-8), 663-676.

Yin, R. K. (2005) Estudo de caso: planejamento e métodos. (3 ed.) Porto Alegre: Bookman, 2005. 
Data da submissão: 13/05/2017

Data de aceite: 22/11/2017 